\title{
Article \\ LED Rail Signals: Full Hardware Realization of Apparatus with Independent Intensity by Temperature Changes
}

\author{
Giuseppe Schirripa Spagnolo $^{1}$ (D) and Fabio Leccese ${ }^{2, *(D)}$ \\ 1 Dipartimento di Matematica e Fisica, Università Degli Studi “Roma Tre", 00146 Roma, Italy; \\ schirrip@uniroma3.it \\ 2 Dipartimento di Scienze, Università Degli Studi “Roma Tre", 00146 Roma, Italy \\ * Correspondence: leccese@uniroma3.it
}

Citation: Schirripa Spagnolo, G.; Leccese, F. LED Rail Signals: Full Hardware Realization of Apparatus with Independent Intensity by Temperature Changes. Electronics 2021, 10, 1291. https://doi.org/ 10.3390/electronics10111291

Academic Editor: Igor Filanovsky

Received: 14 April 2021

Accepted: 25 May 2021

Published: 28 May 2021

Publisher's Note: MDPI stays neutral with regard to jurisdictional claims in published maps and institutional affiliations.

Copyright: (c) 2021 by the authors. Licensee MDPI, Basel, Switzerland. This article is an open access article distributed under the terms and conditions of the Creative Commons Attribution (CC BY) license (https:/ / creativecommons.org/licenses/by/ $4.0 /)$.
Abstract: Nowadays, signal lights are made using light-emitting diode arrays (LEDs). These devices are extremely energy efficient and have a very long lifetime. Unfortunately, especially for yellow/amber LEDs, the intensity of the light is closely related to the junction temperature. This makes it difficult to design signal lights to be used in naval, road, railway, and aeronautical sectors, capable of fully respecting national and international regulations. Furthermore, the limitations prescribed by the standards must be respected in a wide range of temperature variations. In other words, in the signaling apparatuses, a system that varies the light intensity emitted according to the operating temperature is useful/necessary. In this paper, we propose a simple and effective solution. In order to adjust the intensity of the light emitted by the LEDs, we use an LED identical to those used to emit light as a temperature sensor. The proposed system was created and tested in the laboratory. As the same device as the ones to be controlled is used as the temperature sensor, the system is very stable and easy to set up.

Keywords: light emitting diode (LEDs); LED temperature dependency; light signals; temperature control; flexible electronics

\section{Introduction}

Currently, road, airport, nautical, and railway infrastructures tend to use signaling lights made with light emitting diodes (LEDs). In fact, LED signaling lights offers innumerable advantages compared with traditional lamps. LED employment allows for the realization of devices that are long and energy efficient. Therefore, you can make signals with greater reliability and lower maintenance costs.

In road and railway infrastructures, signs use red, yellow/amber, and green lights (sometimes white and blue are also used). The color of the signal lights must be perceived individually. For this reason, various government agencies have defined the light intensity and the chromatic quality of the light source [1]. For applications in the automotive, aeronautical, railway, and naval sectors, different colors are defined in terms of the Commission Internationale d'Eclairage (CIE) chromaticity coordinates [2].

The chromatic regions within which the aspects of the Italian railway signals must be placed (UNI9296-UNIFER standard) are shown in the CIE diagram (Figure 1) [3]. Observing Figure 1, one immediately notices that the chromatic limits for red and yellow are very stringent. The classic signals obtain the correct chromaticity using appropriate optical filters, which lower the energy efficiency of the system. By using LEDs with a sufficiently narrow emission line, it is possible to avoid the use of optical filters, which increase production costs and make the system less robust. 


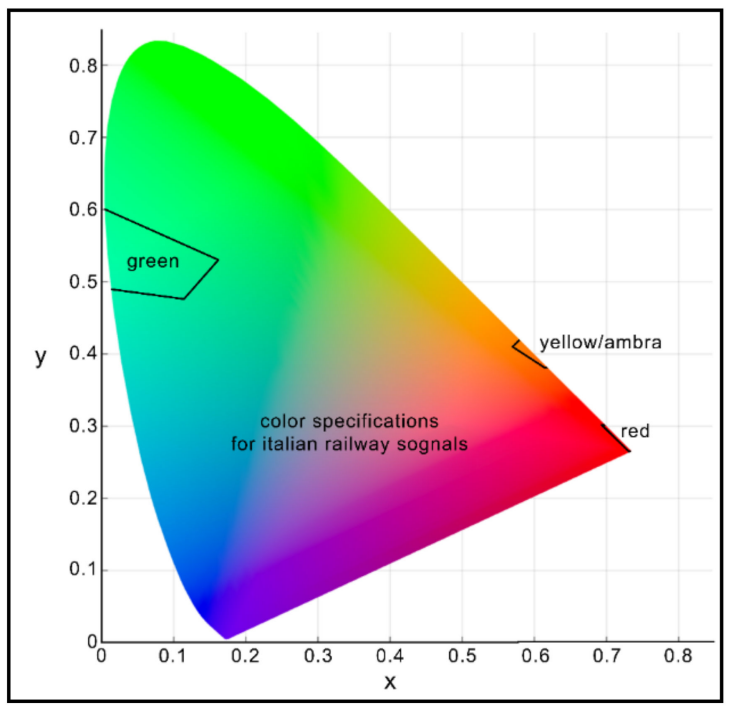

Figure 1. Commission Internationale d'Eclairage (CIE) chromaticity areas for red, yellow, and green aspects of the Italian railway signaling.

Looking at the high-power LED technology currently available, it is easy to see that red, amber, and yellow LEDs are made of aluminum indium gallium phosphide (AlInGaP). For shorter wavelength, (green, blue, and white LEDs) the material used is indium gallium nitride (InGaN). Using these materials, LEDs with luminous efficiency (lumens per watt) suitable for signaling have been developed [4,5].

These semiconductors have an adjustable energy gap by varying the mole fractions. In the InGaN alloy, increasing the mole fraction of InN results in a decrease in the energy gap. Consequently, there is an increase in the wavelength of the emitted light. In InGaN LEDs, the emitted light is tunable from UV-A $(\sim 360 \mathrm{~nm})$ to yellow / green $(\sim 580 \mathrm{~nm})$. Using AlInGaP instead, the emitted color can be changed by varying the mole fraction of AlInP, and colors ranging from yellow $(\sim 580 \mathrm{~nm})$ to deep red $(\sim 650 \mathrm{~nm})$ can be obtained [6]. For InGaN and AlInGaP, Figure 2 shows how the emitted color changes as a function of the molar fractions.

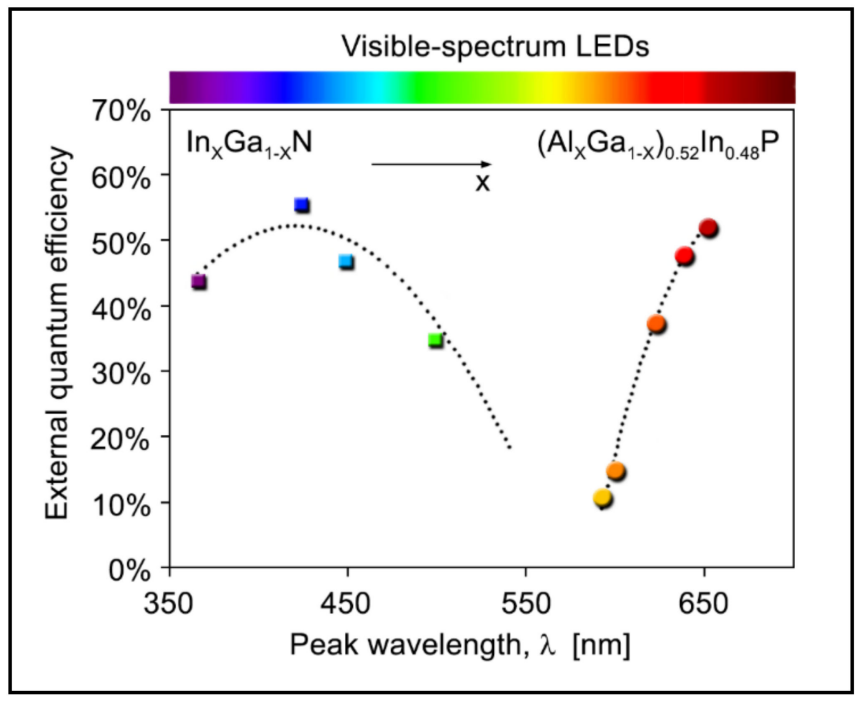

Figure 2. Typical external quantum efficiency and relative emission spectrum vs. molar fractions for indium gallium nitride ( $\mathrm{InGaN}$ ) and aluminum indium gallium phosphide (AlInGaP) light-emitting diode arrays (LEDs). Here, external quantum efficiency is a fraction of the number of photons emitted outside of the semiconductor with respect to those generated overall within it. 
Considering the performance of InGaN and AlInGaP LEDs, it is possible to understand the difficulties associated with the yellow color. As already mentioned, in InGaN LEDs, it is possible to shift the light emitted towards longer wavelengths (smaller energy gap), increasing the concentration of Indium within the active layer. On the other hand, the greater concentration of Indio causes, within the lattice, a greater fluctuation of the gap, with consequent widening of the emitted spectral line (lower color purity). Generally, if the color of the radiation is not sufficiently pure, it moves away from the edge of the CIE diagram and goes outside the limits established by the standards [7]. Figure 3 shows the typical emission spectrum of a yellow INGaN LED. For comparison, the spectrum of a yellow AlInGaP LED is also shown.

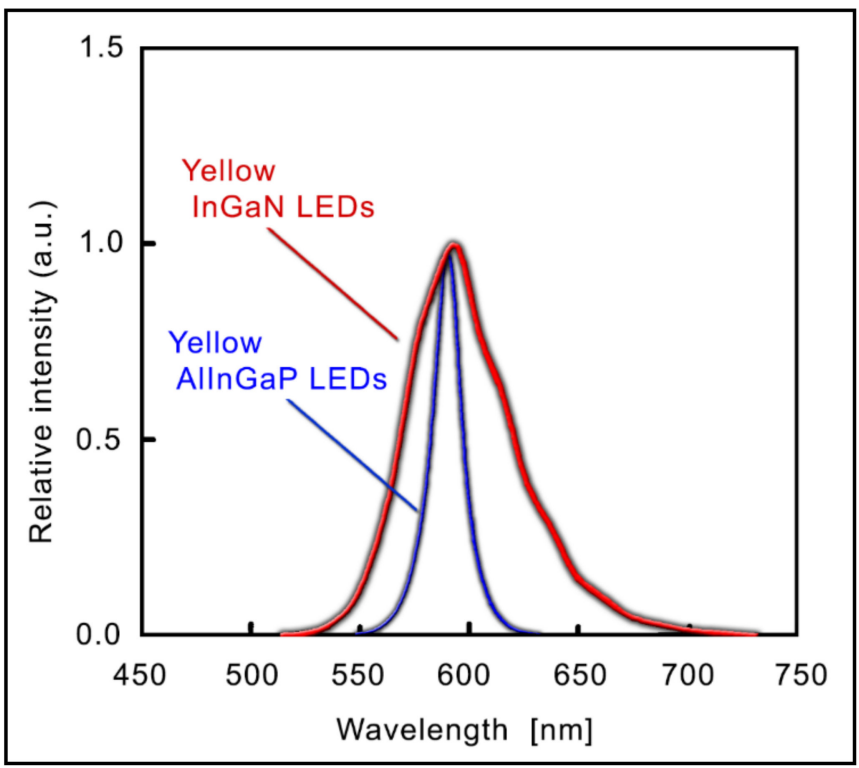

Figure 3. Typical emission spectra of yellow InGaN and yellow AlInGaP.

Unfortunately, LEDs with a low mole fraction of AlInP (those emitting at a low wavelength-yellow LEDs) have a strongly temperature-dependent emission intensity and wavelength. Figure 4a shows the output power of blue/green InGaN and yellow/red AlInGaP LEDs as a function of the temperature. Figure $4 \mathrm{~b}$ shows the variation of the wavelength and intensity vs. temperature of a typical AlInGaP LED. These behaviors of InGaN and AlInGaP make it difficult to design the yellow aspect in signal lights.

Currently, LED devices specifically made for signaling are commercially available. Although the standards prescribe a wide range of temperature variations (generally $-25^{\circ} \mathrm{C}$ to $80^{\circ} \mathrm{C}$ ) for the red and green aspects (as well as blue and white), there is no problem in producing signals that are fully compliant. On the contrary, the realization of the yellow aspect is critical. When LED light signals operate in climates with high temperature variations without a mechanism capable of compensating for these variations, it is impossible to manufacture devices with a yellow color light that comply with regulatory requirements.

The problem of yellow LED light signals is well known. In fact, some companies produce LEDs that emit yellow light by coupling LED blue with special phosphors. With this expedient, it is possible to achieve LEDs with stable photometric characteristics [8]. Although blue LEDs have a high reliability, many studies have shown that phosphors can degrade severely over the life of the device. This is mainly due to the high temperature levels reached by the LED during operation [9-11].

To use phosphor-free AlInGaP LEDs, several solutions have been implemented [12-17]. 


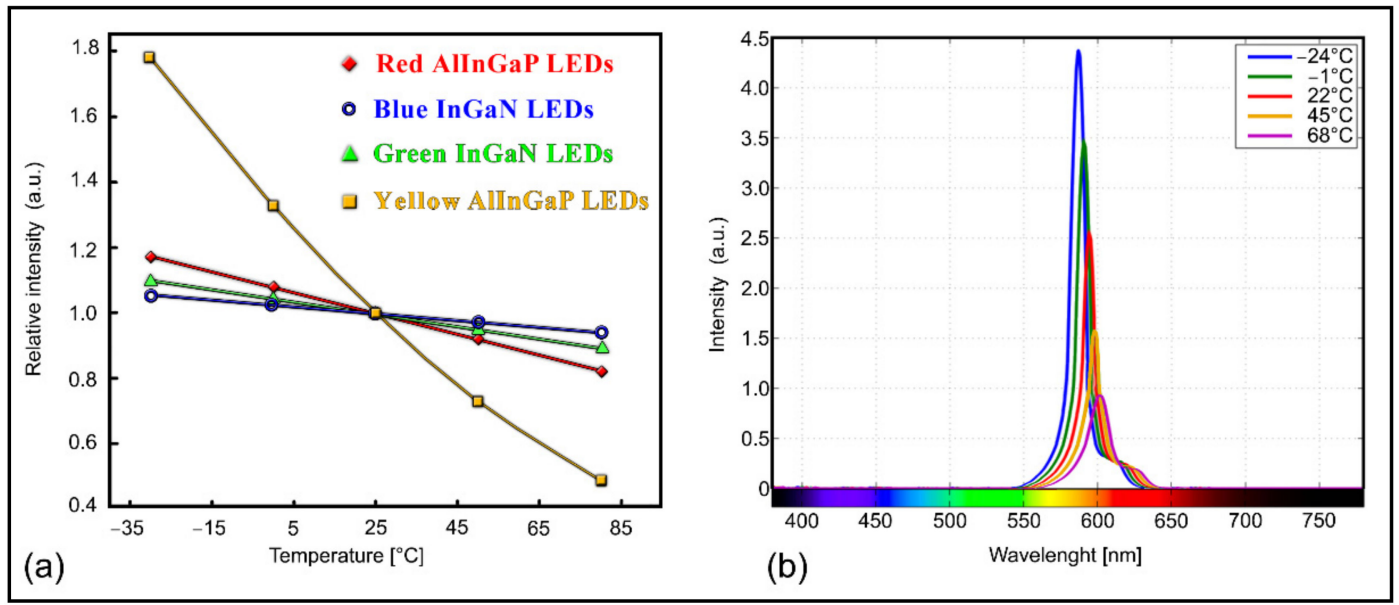

Figure 4. (a) Output power of blue/green InGaN and yellow/red AlInGaP LEDs as a function of temperature. The output power of each LED was normalized to 1.0 at $25^{\circ} \mathrm{C}$. (b) Variations of the wavelength and intensity vs. temperature of a typical AlInGaP LED.

All of these systems work well. Unfortunately, they increase the complexity of the systems. Consequently, with the same reliability there are higher production and maintenance costs. It should also be noted that many standards for "critical applications" of light signals require non-programmable electronic solutions (microprocessors or microcontrollers cannot be used) [3].

In this paper, we will propose a new simple and effective solution. To adjust the intensity of the light emitted by the LEDs, we will use an LED identical to those used to emit light as a temperature sensor. With this solution, a relatively simple system is obtained. Furthermore, it is an apparatus that is simple to adapt to the required operating conditions.

\section{Light Signals: Thermal Effect}

By studying the behavior of the LED parameters as the temperature changes, it is possible to trace the analytical equations that allow for obtaining a nearly invariant light intensity as the temperature varies [18].

Currently, LED devices specifically designed for light signal applications are commercially available. One example is the LY E6SF- DA-6-5A LED manufactured by OSRAM Opto Semiconductors $\mathrm{GmbH}$ [19]. This device is available in various dominant wavelengths (see Figure 5).

\begin{tabular}{lll} 
& $\lambda_{\text {dom-min }}$ & $\lambda_{\text {dom-max }}$ \\
\hline 3 & $583 \mathrm{~nm}$ & $586 \mathrm{~nm}$ \\
\hline 4 & $586 \mathrm{~nm}$ & $589 \mathrm{~nm}$ \\
\hline 5 & $589 \mathrm{~nm}$ & $592 \mathrm{~nm}$ \\
\hline 6 & $592 \mathrm{~nm}$ & $595 \mathrm{~nm}$ \\
\hline
\end{tabular}

Figure 5. Wavelength groups of LY E6SF LEDs. These wavelengths are relative to the bias current $i_{F}=50 \mathrm{~mA}$ and temperature $T=25^{\circ} \mathrm{C}$. The wavelength is typically measured at a current pulse of $25 \mathrm{~ms}$, with an expanded uncertainty of $\pm 1 \mathrm{~nm}$ [19].

In this article, to investigate the yellow aspect of light signals, we used the LY E6SFDA-6-5A model. This type of LED exhibits a dominant wavelength variation that changes relatively little with temperature (see Figure 6). 


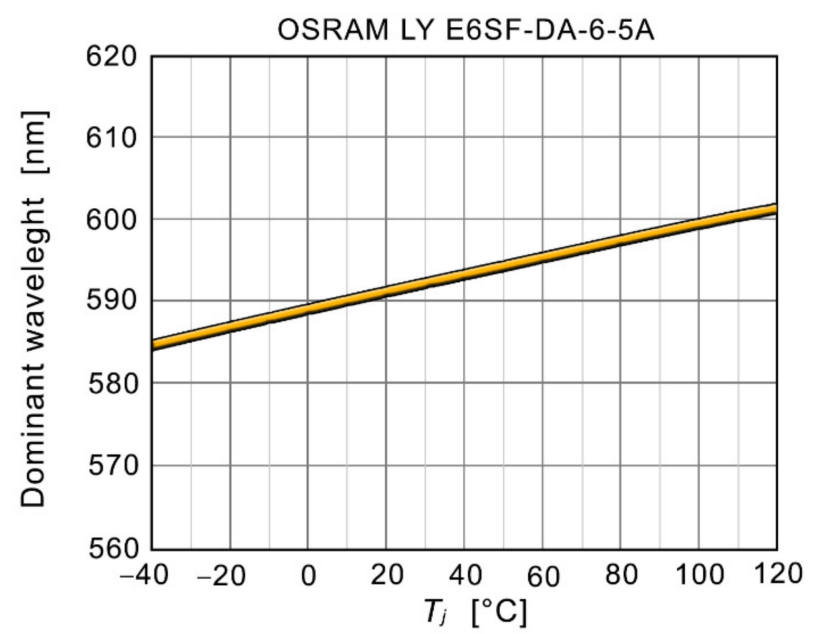

Figure 6. LY E6SF LEDs: changes in dominant wavelength as a function of temperature [19].

Figure 7 shows, for the LY E6SF-DA-6-5S LED, how the chromatic coordinates vary with the temperature changing.

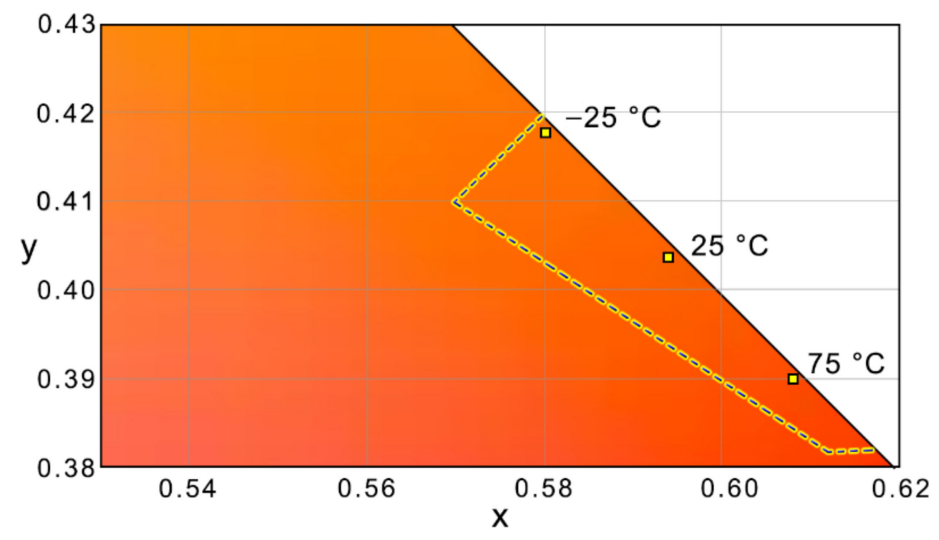

Figure 7. CIE chromaticity areas for yellow aspects of the Italian railway signaling and chromatic coordinates vs. temperature of LY E6SF-DA-6-5A. The chromatic coordinates were calculated using the software LED ColorCalculator [20].

Figure 7 shows how by choosing the device with a dominant wavelength at $25^{\circ} \mathrm{C}$ (in our around 593) centered on the chromatic area defined by the standard, you have an LED capable of maintaining the prescribed color over the entire prescribed temperature range.

Unfortunately, this type of LED, as well as all those made of AlInGaP, has a strongly temperature-dependent intensity of the light emitted (see Figure 8).

The variation of the light intensity with the temperature is not linear. However, it can be considered as almost a straight line in the range of interest $\left(-25^{\circ} \mathrm{C}\right.$ to $\left.80^{\circ} \mathrm{C}\right)$. With this approximation, we can write the normalized intensity at $25^{\circ} \mathrm{C}$, as follows:

$$
I_{V}(T) / I_{V}\left(25^{\circ} \mathrm{C}\right)=-0.0107 \cdot(T-25)+1.01\left(\text { with } T \text { in }{ }^{\circ} \mathrm{C}\right) .
$$

Using a second-degree polynomial fit, you get a perfect overlap between the regression curve and the real one.

$$
I_{V}(T) / I_{V}\left(25^{\circ} \mathrm{C}\right)=-8 \cdot 10^{-6} \cdot(T-25)^{2}-0.0117 \cdot(T-25)+1.01\left(\text { with } T \text { in }{ }^{\circ} \mathrm{C}\right) .
$$

In this case, the improvements obtained with a polynomial regression (see the coefficients of the Equations (1) and (2)) do not justify the complication of the model. 


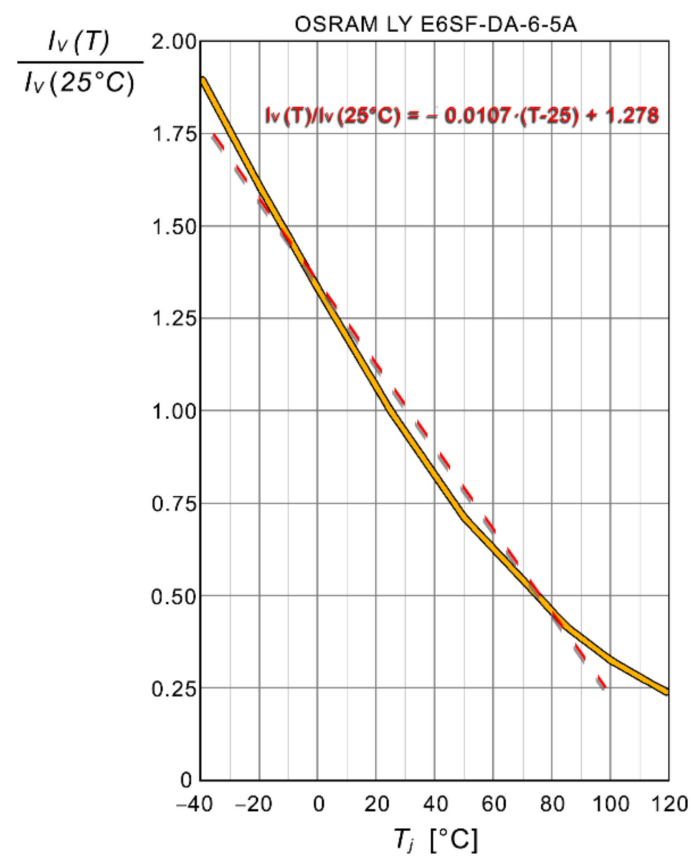

Figure 8. LY E6SF LEDs: temperature dependence of intensity. The linearization line is also shown. $I_{V}$ represents the light intensity emitted by the LED and the $T_{j}$ junction temperature. The light intensity is normalized to 1 when the bias current is $50 \mathrm{~mA}$.

The luminous intensity of an LED, in addition to external parameters, mainly depends on the bias current. Figure 9 shows how the intensity changes as a function of the bias current for the LY E6SF LED.

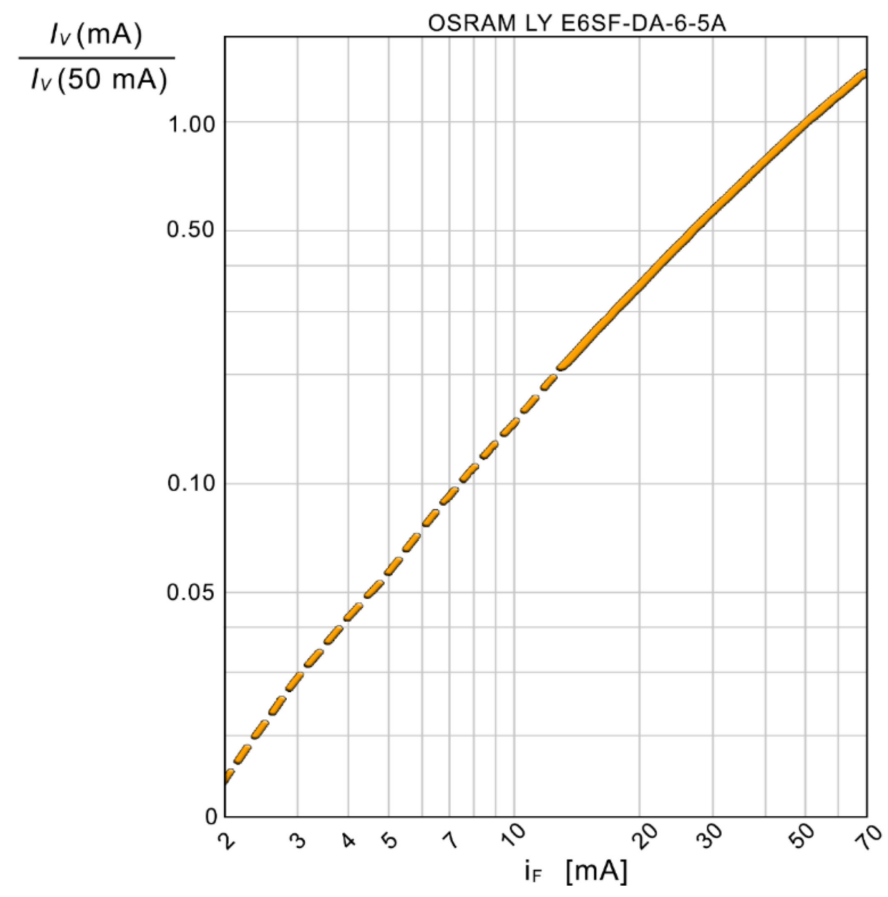

Figure 9. LY E6SF LEDs: intensity vs. bias current when the temperature of the soldering point is $25{ }^{\circ} \mathrm{C}$. $I_{V}$ represents the light intensity emitted by the LED and $i_{F}$ bias current. The light intensity is normalized to 1 when the bias current is $50 \mathrm{~mA}$. 
Although this function is not linear, it can be considered to be a straight line around the bias current of $50 \mathrm{~mA}$. Therefore, we can write the following:

$$
I_{V}(\mathrm{~mA}) / I_{V}(50 \mathrm{~mA})=(1 / 50) \cdot i_{F} \Rightarrow i_{F}=50 \cdot\left[I_{V}(\mathrm{~mA}) / I_{V}(50 \mathrm{~mA})\right] .
$$

Considering the variations of intensity accepted even by the most stringent regulations, the linearization carried out with Equations (1) and with (3) are more than adequate; intensity variations of the order of $\pm 25 \%$ with respect to the normal one are generally accepted [3,21,22].

By combining Equations (1) and (3), we obtain the following:

$$
\left.i_{F}=0.535 \cdot(T-25)+50.5 \text { (in this equation } T \text { is }{ }^{\circ} \mathrm{C} \text { and } i_{F} \text { is } \mathrm{mA}\right) .
$$

Equation (3) represents the analytical form of the current, which makes it possible to compensate for variations in the efficiency of LEDs with temperature.

It is important to note that, for the current flowing through the LEDs to have a compensatory effect on the variation of efficiency, it must behave in an opposite way, that is, an increase in temperature must correspond to an increase in the bias current (for this reason, in the Equation (3) the slope constant was switched from a negative to positive value).

To make the intensity of the LED independent of the temperature, it is essential to have a sensor that reads the temperature and provides this information to the appropriate circuit. In principle, various types of temperature sensors could be used. Unfortunately, not all of these sensors have the same thermal trend as the LEDs that must be compensated for. Furthermore, it is not easy to correlate the measured temperature with that of the LED junction; the latter affects the performance of the LEDs.

As diodes are an excellent temperature sensor, at a constant bias current, the forward voltage vs. temperature is linear [23-25]. Therefore, a LED identical to those used to emit light can be used as a temperature sensor. Furthermore, this LED can be driven with a current equal to that used to drive the LEDs used for signaling. If the signaling LEDs and the one used as a sensor are mounted on the same cooling plate, they have very similar junction temperatures.

Figure 10 shows the forward voltage vs. temperature for LY E6SF LEDs. Forward voltage vs. temperature is not linear. However, it can be considered as almost a straight line in the range of interest $\left(-25^{\circ} \mathrm{C}\right.$ to $\left.80^{\circ} \mathrm{C}\right)$. With this approximation, we can write the normalized intensity at $25^{\circ} \mathrm{C}$ as follows:

$$
V_{F}=-0.0027 \cdot T+2.68\left(T \text { in }{ }^{\circ} \mathrm{C} \text { and } V_{F} \text { in volt }\right) \Rightarrow T=\left(2.68-V_{F}\right) / 0.0027
$$

Using a second-degree polynomial fit you get a perfect overlap between the regression curve and the real one.

$$
V_{F}=-9 \cdot 10^{-6} \cdot T^{2}-0.0033 \cdot T+2.68\left(T \text { in }{ }^{\circ} \mathrm{C} \text { and } V_{F} \text { in volt }\right) .
$$

In addition, in this case, the improvements obtained with the polynomial regression, (see the coefficients of Equations (5) and (6)) do not justify the complication of the model.

Taking into consideration Equations (4) and (5), we have the following:

$i_{F}=0.535 \cdot\left[\left(\left(2.68-V_{F}\right) / 0.0027\right)-25\right]+50.5=568-198.15 \cdot V_{F}\left(i_{F}\right.$ in $\mathrm{mA}$ and $V_{F}$ in volt $)$.

By driving the LEDs with the bias current established with Equation (6), there is an emission of light almost independent of the temperature. 


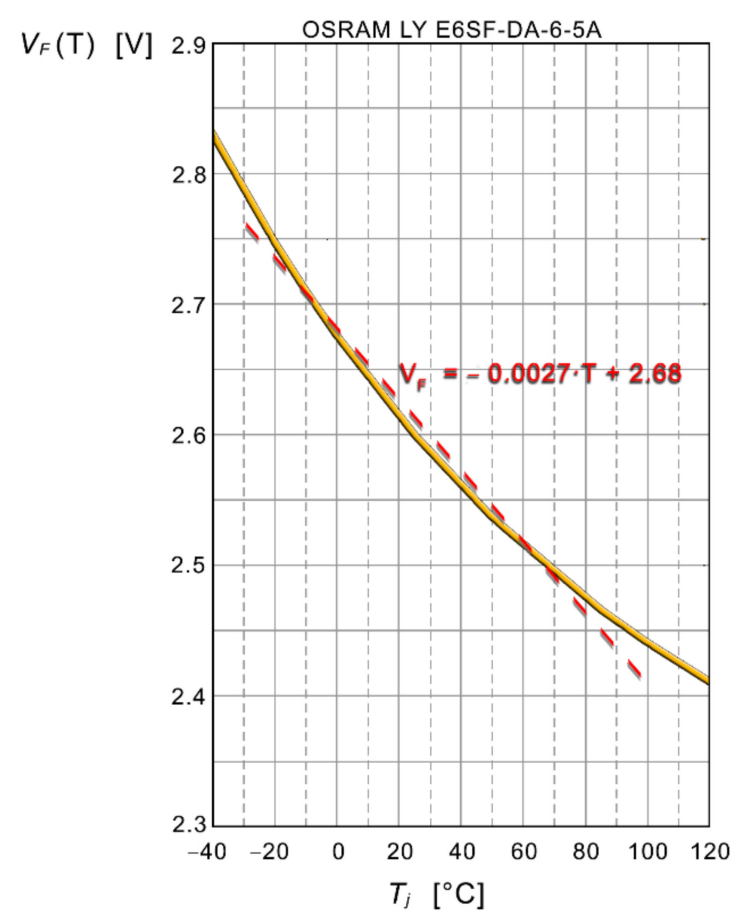

Figure 10. LY E6SF LEDs: forward voltage vs. temperature (current $50 \mathrm{~mA}$ ).

\section{Circuit Solution}

Our aim was to design a driver for LEDs able to compensate for intensity variations related to temperature changes.

The implemented circuit is illustrated in Figure 11.

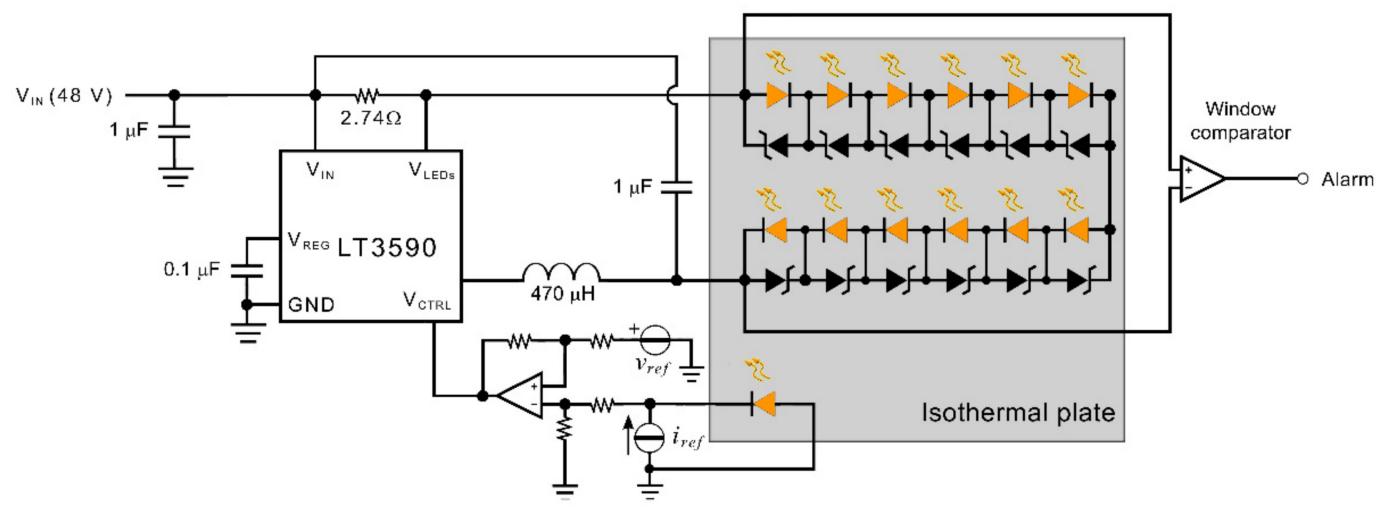

Figure 11. Schematic of the circuit solution. The cluster's current is defined by a classical integrated power-switch in a constant current mode configuration.

Our circuit was designed to drive a cluster of 12 LY E6SF LEDs. In our work, we used LEDs with a forward voltage between 2.5 and $2.65 \mathrm{~V}$. A $5 \mathrm{~V}$ Zener diode was placed in parallel to each LED. If the LEDs were working correctly, the Zener diodes were irrelevant. If an LED was interrupted, it became an open circuit, and the Zener went into conduction. This allowed for the other LEDs to function correctly. The Zener conduction increased the difference of potential present on the LED cluster. The difference of potential across the cluster increased by over $2 \mathrm{~V}$. This voltage increase was detected by the window comparator, which provided a malfunction alarm. The window comparator could also detect if a diode was shorted. In this case, the remaining LEDs continued to function correctly, but the voltage across the cluster decreased by about 2 volts. The window comparator also detected this voltage variation. In a critical signal light, the alarm signaling was important, just as it 
is important that, as far as possible, the system continued to operate if maintenance was not carried out.

In our circuit, to drive the LEDs, we used a commercial integrated circuit LT3590 [26]. It was a fixed frequency buck mode converter. This component, specifically designed to drive LED clusters, had a control terminal ( $\mathrm{V}_{\mathrm{CTRL}}$ ) that allows for adjusting the current to be sent to the cluster. Using a resistor of $2.74 \Omega$ (as shown in Figure 11), in conformity with the specifications of LT3590, we have the following:

$$
i_{F}=58.4 \cdot V_{C T R L} \Rightarrow V_{C T R L}=0.017 i_{F}\left(i_{F} \text { in } \mathrm{mA} \text { and } V_{C R T} \text { in volt }\right) .
$$

Taking into consideration Equations (7) and (8), we have the following:

$$
V_{C T R L}=9.7-3.4 V_{F}\left(V_{F} \text { and } V_{C R T} \text { in volt }\right) .
$$

Equation (9) allows for adjusting the control voltage of the buck converter in order to obtain the light intensity independent of the temperature.

Therefore, by using an LED equal to those used to emit the light positioned on the same heat sink of the LEDs, it was possible to read the junction temperature.

A current generator bias with $50 \mathrm{~mA}$ was used as the LED thermometer; the same nominal current flowed through the light emitting diodes. In our case, we use another LT3590 configured to supply a fixed current of $50 \mathrm{~mA}$ by means of an instrumentation amplifier (INA 122 [27]). This amplifier was adjusted to amplify 3.4. The output of the instrumentation amplifier was sent to the inverting input of a differential amplifier with unity gain. On the other hand, a reference voltage of $9.7 \mathrm{~V}$ was sent to the non-inverting input. In this way, the correct voltage $\mathrm{V}_{\mathrm{CTRL}}$ necessary to drive the LEDs was obtained. The correct reference voltage was obtained via an adjustable reference voltage circuit [28]. This circuit made use of a precise voltage reference and an operational amplifier.

\section{Experimental Results}

To verify the effectiveness of the proposed system, an experimental set-up was implemented. The LEDs, both used for signaling and one used to measure the temperature, were soldered onto an isothermal plate. Afterwards the LEDs and the plate were mounted on a temperature-controlled appliance. The temperature of the plate was controlled by a PID-controller combined with the Peltier element. The spectral power distribution was measured from $380 \mathrm{~nm}$ to $780 \mathrm{~nm}$ with the spectrometer. The schematic of experimental set-up is shown in Figure 12.

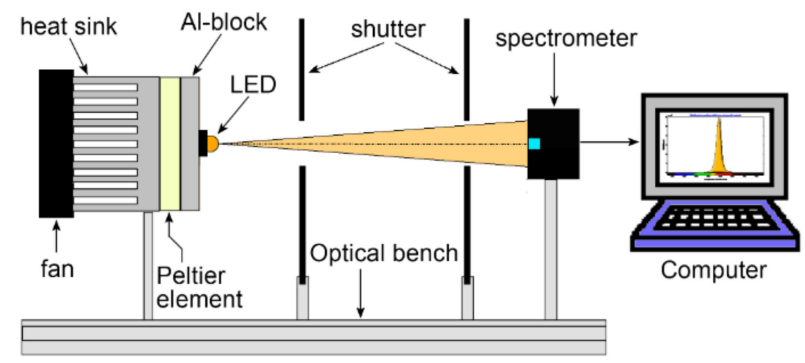

Figure 12. Outline of the measurement structure.

In our experiment, we varied the temperature of the isotherm plate. For six different temperatures, we obtained the intensity and the emission spectrum. Figure 13 shows the data obtained without the stabilization system.

Then, we activated the temperature variation compensation circuit. Figure 14 shows how light intensity changes for temperature variations in the $5^{\circ} \mathrm{C}-55^{\circ} \mathrm{C}$ range.

Figure 14 shows that the proposed system worked very well. The residual change in 
intensity was widely acceptable; it was much lower than that tolerated by even the most restrictive regulations.
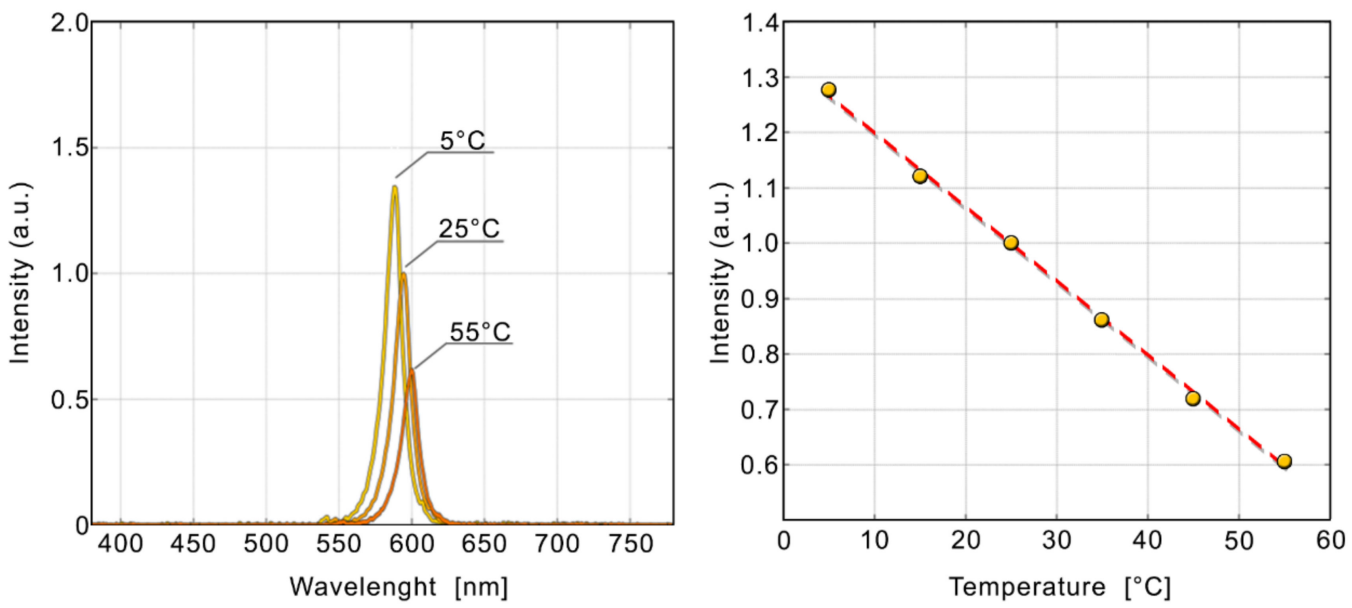

Figure 13. Characterization of the optical properties of the LY E6SF LED as the temperature varies. (Left) Emission spectrum vs. temperature. (Right) Emission efficiency vs. temperature.

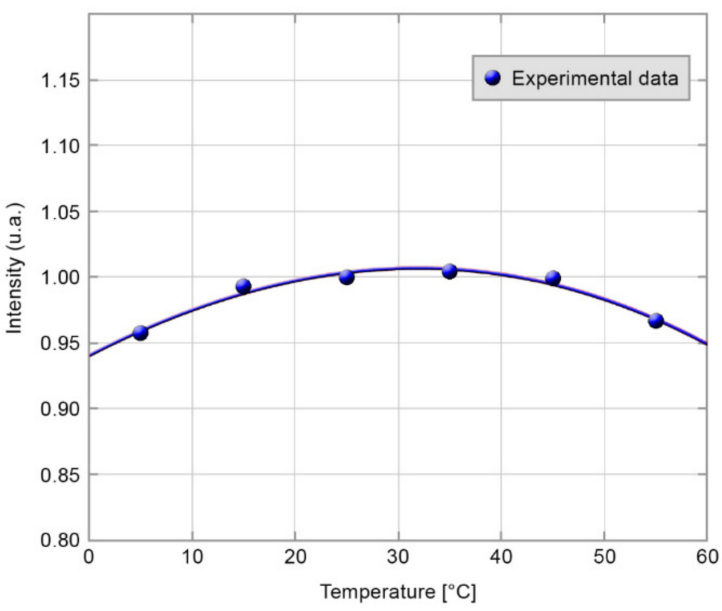

Figure 14. Stabilization of intensity as the temperature changes: experimental results.

Figure 15 shows how the chromatic coordinates of the LEDs varied when they were driven through our temperature compensation system.

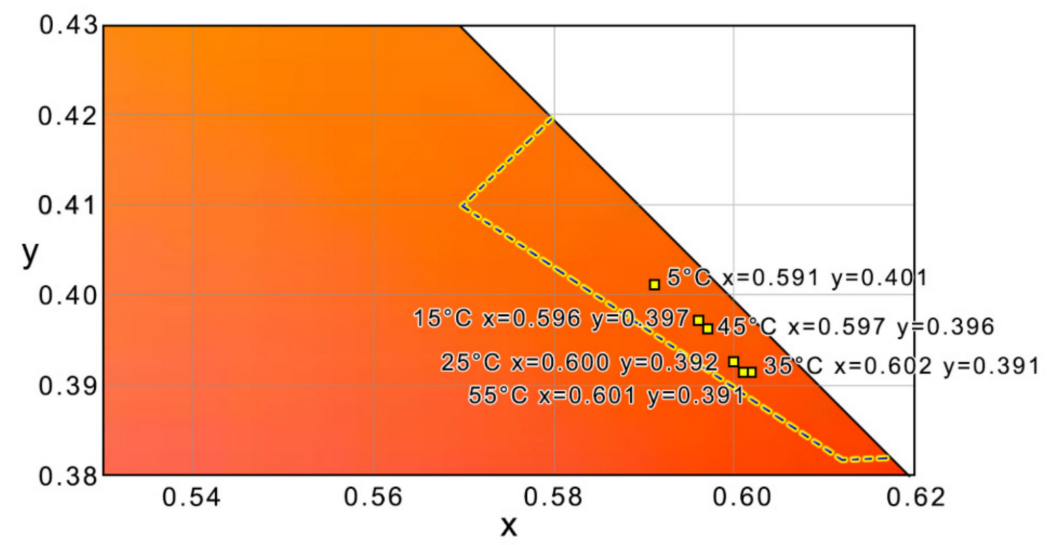

Figure 15. Compliance with the colorimetric standards of the LED: experimental results. 


\section{Conclusions}

Light emitting diodes (LEDs) are currently the most widely used technology in the field of signaling. Unfortunately, light sources made with this technology have photometric characteristics dependent on the temperature. This makes it difficult to achieve signal light that fully complies with regulations. In addition, in critical applications, the use of microprocessors and/or microcontrollers is often not recommended. In this paper, we proposed a simple and reliable system that solves this problem. An LED identical to those used as a light source is used as a temperature sensor. The system was designed, built, and tested in the laboratory. It was designed around the standards used for Italian railway signals. In any case, it is easily adaptable to other types of signals and other standards.

Author Contributions: Conceptualization, G.S.S. and F.L.; methodology, G.S.S. and F.L.; software, G.S.S. and F.L.; validation, G.S.S. and F.L.; formal analysis, G.S.S. and F.L.; investigation, G.S.S. and F.L.; resources, G.S.S. and F.L.; data curation, G.S.S. and F.L.; writing—original draft preparation, G.S.S. and F.L.; writing-review and editing, G.S.S. and F.L.; visualization, G.S.S. and F.L.; supervision, G.S.S. and F.L.; project administration, G.S.S. and F.L.; funding acquisition, G.S.S. and F.L. Both authors have read and agreed to the published version of the manuscript.

Funding: This research received no external funding.

Conflicts of Interest: The authors declare no conflict of interest.

\section{References}

1. Traffic Control Equipment-Signal Heads, en 12368:2015. Available online: https://www.en-standard.eu/bs-en-12368-2015 -traffic-control-equipment.-signal-heads/ (accessed on 10 April 2021).

2. Commission Internationale de l'Eclairage (CIE). Colorimetry, 3rd ed.; CIE: Vienna, Austria, 2018. [CrossRef]

3. UNIFER 9296, Colore dei Segnali Luminosi Ferroviari. 1988. Available online: https://www.rfi.it/it/Sicurezza-e-tecnologie/ norme-di-esercizio.html (accessed on 21 May 2021).

4. Li, S.S. Light-Emitting Devices. In Semiconductor Physical Electronics; Springer Science and Business Media LLC.: Berlin/Heidelberg, Germany, 2007; pp. 458-512.

5. Zhu, D.; Humphreys, C.J. Solid-State Lighting Based on Light Emitting Diode Technology. In Optics in Our Time; Metzler, J.B., Ed.; Springer: Cham, Switzerland, 2016; pp. 87-118.

6. Krames, M.R.; Shchekin, O.B.; Mueller-Mach, R.; Mueller, G.O.; Zhou, L.; Harbers, G.; Craford, M.G. Status and Future of High-Power Light-Emitting Diodes for Solid-State Lighting. J. Disp. Technol. 2007, 3, 160-175. [CrossRef]

7. Mukai, T.; Yamada, M.; Nakamura, S. Characteristics of InGaN-Based UV/Blue/Green/Amber/Red Light-Emitting Diodes. Jpn. J. Appl. Phys. 1999, 38, 3976-3981. [CrossRef]

8. Mills, A. Phosphors development for LED lighting. III-Vs Rev. 2005, 18, 32-34. [CrossRef]

9. Meneghini, M.; Trevisanello, L.-R.; Meneghesso, G.; Zanoni, E. A Review on the Reliability of GaN-Based LEDs. IEEE Trans. Device Mater. Reliab. 2008, 8, 323-331. [CrossRef]

10. Meneghesso, G.; Meneghini, M.; Zanoni, E. Recent results on the degradation of white LEDs for lighting. J. Phys. D Appl. Phys. 2010, 43, 354007. [CrossRef]

11. Meneghini, M.; Lago, M.D.; Trivellin, N.; Meneghesso, G.; Zanoni, E. Thermally Activated Degradation of Remote Phosphors for Application in LED Lighting. IEEE Trans. Device Mater. Reliab. 2012, 13, 316-318. [CrossRef]

12. Grossman, H.; Lambertville, N.J. LED Driving Circuitry with Light Intensity Feedback to Control Output Light Intensity of an LED. U.S. Patent 6,153,985, 28 November 2000. Available online: https://www.google.com/patents/US6153985 (accessed on 10 April 2021).

13. Wu, C.H.; Chuang, H.J. LED Power Supply with Temperature Compensation. U.S. Patent 6,111,739, 29 August 2000. Available online: https: / / www.google.com/patents/US6111739 (accessed on 10 April 2021).

14. Papalillo, D.; Del Vecchio, P.; Spagnolo, G.S. LED Applications in Road and Railway Signals: Is It Possible to Fit Specifications. In Photonics, Devices, and Systems V; International Society for Optics and Photonics: Bellingham, WA, USA, 2011 ; Volume 8306. [CrossRef]

15. Spagnolo, G.S.; Papalillo, D.; Martocchia, A. Light emitting diode in stationary transportation applications: Wavelength response to varying temperature. In Proceedings of the Light-Emitting Diodes: Materials, Devices, and Applications for Solid State Lighting XVI, San Francisco, CA, USA, 21-26 January 2012; Volume 8278. [CrossRef]

16. Spagnolo, G.S.; Papalillo, D.; Martocchia, A.; Makary, G. Application of LEDs to traffic signal. In Proceedings of the 11th International Conference on Environment and Electrical Engineering, Venice, Italy, 18-25 May 2012; pp. 864-868.

17. Spagnolo, G.S.; Papalillo, D.; Malta, C.; Vinzani, S. Led railway signal vs full compliance with colorimetric specifications. Int. J. Transp. Dev. Integr. 2017, 1, 568-577. [CrossRef] 
18. Bera, S.; Singh, R.; Garg, V. Temperature behavior and compensation of light-emitting diode. IEEE Photonics Technol. Lett. 2005, 17, 2286-2288. [CrossRef]

19. OptoSemicondutors OSRAM, LS E6SF Datasheet. Available online: https://dammedia.osram.info/media/resource/hires/ osram-dam-6811438/LY\%20E6SF_EN.pdf (accessed on 10 April 2021).

20. OSRAM, LED ColorCalculator. Available online: https://www.osram.us/cb/tools-and-resources/applications/ledcolorcalculator/index.jsp (accessed on 21 May 2021).

21. Gibson, K.; Haupt, G.; Keegan, H. Specification of railroad signal colors and glasses. J. Res. Natl. Inst. Stand. Technol. 1946, 36, 1-30. [CrossRef] [PubMed]

22. RailCorp. SPG 157 Specification Light Signals, July 2019. Available online: https://www.transport.nsw.gov.au/industry/assetstandards-authority / find-a-standard/light-signals-15 (accessed on 21 May 2021).

23. Sclar, N.; Pollock, D. On diode thermometers. Solid-State Electron. 1972, 15, 473-480. [CrossRef]

24. Acharya, Y.B.; Vyavahare, P.D. Study on the temperature sensing capability of a light-emitting diode. Rev. Sci. Instrum. 1997, 68, 4465-4467. [CrossRef]

25. Iskrenovic, P.S. Systematic error of diode thermometer. Rev. Sci. Instrum. 2009, 80, 084901. [CrossRef] [PubMed]

26. Linear Technology LED Driver LT3590 Datasheet. Available online: https://www.analog.com/media/en/technicaldocumentation/data-sheets/3590f.pdf (accessed on 10 April 2021).

27. Texas Instruments INA122 Instrumentation Amplifier Datasheet. Available online: https://www.ti.com/lit/ds/symlink/ina122 .pdf?ts=1621628908085\&ref_url=https\%253A\%252F\%252Fwww.ti.com\%252Fproduct\%252FINA122 (accessed on 10 April 2021).

28. Texas Instruments, Adjustable Reference Voltage Circuit. Available online: https://www.ti.com/lit/an/sboa246/sboa246.pdf? ts $=1621630715400 \& r e f \_u r l=h t t p s \% 253$ A\%252F\%252Fwww.google.it\%252F (accessed on 10 April 2021). 